\title{
Scientific approach to quantitative measurement and economic processes research in corporate management
}

\author{
Oliver Orlov ${ }^{1, *}$, Yevheniya Ryasnykh $^{1, * *}$, Kathrin Dumanska ${ }^{1, * * *}$, and Olena Savchenko ${ }^{1, * * * *}$ \\ ${ }^{1}$ Khmelnytskyi National University, 11 Instytutska Str., Khmelnytskyi, 29000, Ukraine
}

\begin{abstract}
Theoretical and methodological studies of quantitative measurement problems of the outcome economic indicators in corporate management are examined in the article. The author's vision of scientific exploration as one of the corporate management optimization directions is offered and the basis of such direction as profit margin calculation methodology is presented. It is also suggested to solve problems of quantitative measurement of basic economic processes by using allocation of fixed costs in proportion to profit margin. The methodological basis for evaluating cost-effectiveness with the help of profit margin ratio is developed by the authors. It was revealed that fixed costs are the conditions for doing business and the functional purpose of profit margin is the fixed costs coverage. It is proved that in case of multi-assortment production one of the most effective corporate management approaches to cost estimation and pricing is the profit margin concept provided in this article. One of the advantages of proposed profit margin concept is the availability of special tools revealing the resources that allow covering fixed costs and generating profit with a given level of cost-effectiveness. The obtained results of further adoption can be applied as element of corporate management of manufacturing companies and enterprises in conditions of multi-assortment production and changeable economic environment
\end{abstract}

\section{Introduction}

The quantitative measurement problems in corporate management have been studied by different economists during decades. Great interest among scientists was aroused by book "Economics: Principles and Policy" [1]. According to W. J. Baumol and A. S. Blinder, the degree of dissatisfaction with the theory is growing among practitioners, which does not equip us with tools for analysis and does not lend itself to empirical testing. A similar position is taken by H. A. Simon, a Nobel prizewinner (1978), who underlined, that: "It would be a gross delusion to believe that scientific research cannot be fundamental if its results are primarily of an applied nature or if it is carried out in response to problems raised by everyday life. The real world is probably the most abundant of all sources of serious problems requiring fundamental scientific research" [2]. The same idea is carried out in the Nobel lecture of M. Allais: "In my approach, I never went from theory to facts, but, on the contrary, tried to deduce an explanatory thread from the facts, without which they seem incomprehensible and useless" [3]. And R. Coase directly demands: "What we need is an increase in empirical research" [4].

In its turn, the problem of quantitative measurement of economic calculations was put forward in his Nobel lecture by F. A. von Hayek and accordingly his lecture was called "Pretence of Knowledge". In his opinion, un-

\footnotetext{
*e-mail: pro_univer@ukr.net

**e-mail: pro_univer@ukr.net

***e-mail: KathrynD@bigmir.net

****e-mail: savchenkoov@i.ua
}

like the natural sciences, in economics all the circumstances that will determine the outcome of the process will never be fully known or measured. Moreover, he is negative about the requirement of quantitative measurements in economics. That's why in his opinion, the problems are not connected with theory, but with attempts to apply theories to a specific situation in the real world. "If we want to protect the reputation of science and prevent groundless claims of knowledge based on superficial similarities with the methods of physical sciences, it is necessary to direct great efforts to expose such claims, some of which have now turned into the group interests of authoritative university departments" [5]. F. A. von Hayek's views on the role of economic and mathematical modeling as an instrument of economic science are of interest. Further, F. A. von Hayek expresses his gratitude to K. Popper for the proposed test, by means of which it is possible to distinguish what deserves a scientific status from what is not. According to F. A. von Hayek, many of the doctrines that were recognized as scientific would not have passed this test. F. A. von Hayek is a supporter of extreme liberalism, an opponent of any state regulation. In his opinion, the results of research on such a complex phenomenon as the market will never be fully known and measured. Indeed, at the macroeconomics level, it is very difficult to achieve quantitative measurements of economic processes, as these studies are based on the use of the method of oversimplification and these results are very difficult to use in real practice.

It is necessary to emphasize that the problem of cost allocation in profit margin formation process, as one of 
the basic problems of quantitative measurement in corporate management, is supposed to be one of the most important for manufacturing companies. Methods of costs allocations are noticed as the most problematic in corporate management of multi-assortment production, but at the same tame, it can be considered as the basis of profit margin formation methodology. There is no generally accepted overall method of the cost allocation with some degree of grounded justification for its effectiveness. Many Ukrainian companies (as well as Czech Republic ones, for example) keep in use the traditional techniques of fixed cost allocation using wages, production volumes etc. as the basis for allocating these costs.

According to scientific view of P. Novák and B. Popesko: "companies are now very often lacking sophisticated tool for proper identification and allocation of costs and hence their proper factored into the price of products" and as they summarize: "most companies, up to $70 \%$, allocate their overhead costs on the basis of historical overhead costs evolution. This situation is most striking especially in small and medium-sized companies. And a fluctuation in capacity utilization often leads to inadequate coverage of fixed (overhead) costs" [6]. One of the objectives of their research was to find out the costing methods used by companies in Czech Republic. In fact, many companies keep in use the traditional techniques known from 1970s, as well as companies in Ukraine.

At the same time, R. Lin and Z. Chen revealed two kinds of fixed input allocation problems: the problem of fixed cost allocation across a set of comparable decision making units (DMUs) and that of fixed resource allocation with sharing a common output target among DMUs. As the result, the authors adopt the data envelopment analysis technique to build models for solving two problems of allocating the above two kinds of fixed inputs among all DMUs and common output target sharing problem that is accompanied with the fixed resource allocation, respectively. This method is quite specific and based on special algorithms [7].

Considering another's scientific view points it is necessary to admit that K. Janovská, S. Vilamová, M. Piecha, J. Kutác, R. Kozel and J. Citbajová proposed model for allocation of overhead activity costs which focuses on the allocation of overhead costs and calculation of assignment rates of overhead activities, which mutually cooperate. The model enables the objective stipulation of assignment rates of mutually cooperating overhead activities using exact economic-mathematical methods - the Leontief structural model [8]. Some studies do not pay attention to cost allocation methods, giving general review of CVP analyses and break-even calculations [9]. The practical application of breakeven analysis in production planning and control in different countries is presented by other authors [10], but the problem of overheated costs as usual is out of consideration. M. Potkanya and L. Krajcirova [11] supposed to calculate break-even point of each product line as product line revenue in total company revenue, divided by average selling price of the product, multiplied to BEP of Company. These calculations will carry over revenue of certain product in the whole structure to weight of the product line in break-even point of company. These authors also suggest distributing fixed costs on the base of variant costs, which we believe in totally wrong.

Such authors as P. T. M. Ingenbleek, R. T. Frambach and T. M. M. Verhallen [12] believe that they provide insight into the relationship between pricing practices and new product performance by difference between new product market performance and price level as two major outcomes of new product pricing. The authors consider that value-informed pricing has an unjustified positive impact on relative price level and market performance. The effects of cost-informed and competition-informed pricing may differ depending upon the objective (market performance or higher prices), product conditions (product advantage and relative product costs), and market condition (competitive intensity). As the result, it is suggested to consider different factors in new product pricing: the explicit pricing objective; product advantages, relative product costs, and competitive intensity. The regression analyses was used to determine interact of variables. The research was based on collected data from managers who recently had been engaged in such a decision-making process.

Authors group of D. De Toni, G. S. Milan, E. B. Saciloto and F. Larentis [13] consider suggesting and testing a theoretical model showing the impacts of pricing policy on corporate profitability. For this purpose 150 companies of Northeast of Rio Grande do Sul State, Brazil were under the consideration. The authors used 15 questions related to the aspects considered or not in the price defining process. The factor analysis was made. The data analysis became the basis of conclusions made by researches. As we consider, this can not be understood as methodology of pricing policy.

In resent article A. Farm offers a theory of pricing in consumer markets that views cost-plus pricing and valuebased pricing in conjunction with price competition and price leadership, including, in particular, competitive price leadership. Various theories of pricing were given with cost-plus pricing, value-based pricing etc. It is necessary to notice, that "cost-plus pricing also implies, - what authors agree with, - that indirect costs and normal profits are allocated to a firm's products in proportion to their direct costs" and it also stated in the article, that: "the markup is obtained by summing two ratios, namely the ratio of indirect costs to direct costs for estimated sales, and the ratio of normal profits to direct costs for estimated sales" [14]. The next calculations we believe were mistaken because of using direct costs as a base for allocation of indirect costs. On the other hand it is underlined that there are many variants of cost-plus pricing depending on the systems of cost accounting, different definitions of normal profits, and different markup techniques.

Taking into account the view point of B. Cohen and M. Neubert, who emphasize that product-oriented pricing, company-oriented, competition-oriented pricing should be considered in multi-assortment production. The authors refer to R. Luostarinen and M. Gabrielsson [15] who studied 89 companies in Finland, "these companies often bypassed cost-informed pricing (setting a product's price 
floor) by choosing below cost pricing for their first international customer, and thereafter applying value-added pricing based on the benefits brought to its customers" [16]. That means the company-oriented pricing (cost informed pricing to be more precise) with its pros and contras is used very often in lot of industries and our developments can be useful there as well.

"In this case, it should be underlined three main systems necessary to solve company's or enterprise's sustainability tasks connected with accumulation of potential of success in managerial decision making. Such systems include: strategic planning, implementation and control; these systems are respectively responsible for the development, implementation and revision of current strategy" [17] and manufacturing activity of legal entity as well. Thus, complex application of these systems in corporate managerial decisions is one of the effective company's management directions in machine-building production.

Practically, view point of these authors on the economic processes research in corporate management is capable of future gradual implementation of theory into real life. In this article we try, through empirical research, to consider specific problems that are encountered in real practice and to propose methods for solving these problems. Quantitative measurements are especially difficult in a multi-assortment manufacturing environment. Obviously, therefore, scientists try to carry out their calculations in the single-item production conditions. According to the research, for a market economy, especially at the present stage, characteristic feature is the rapidity of structural changes that relate to all areas of the enterprise, and this is especially true for the problems of calculating the prime cost, profit, cost-effectiveness and prices. These indicators are mutually influenced by changes in the scale of production, the structure of the assortment, prices, the value of fixed and variable costs. In this situation, it is very important to clearly define the components of this relationship and which of these elements play a decisive role in corporate decision making process.

The importance of break-even calculations distribution of fixed costs proportionally to profit margin and the necessity of pricing on the break-even ratio basis in the frame of corporative management is observed and grounded in comparative calculation examples of the article. Taking into consideration that large enterprises with comparative management systems are interested in high volumes of multi-assortment production and therefore in large sales revenue we have chosen two profitably known enterprises in our region for break-even calculations, because such indicators are more evident for companies. In conditions of multi-assortment production it is the corporations, large enterprises that should take into account target profits, pricing, fixed costs and cost-effectiveness since these indicators cannot be calculated in isolation from output structure and scale production changes.

Before starting the specific study it is necessary to define clearly the list of problems that interfere with making effective management decisions and, after forming the correct problem view point, the necessary decision-making tools can be developed.

\section{Methodology of researching}

The goal of the research is the elaboration of methodological decision making apparatus for corporate management on the basis of economic-mathematical modeling that can accumulate information on assortment structure, pricing, fixed and variable costs and cost-effectiveness.

At most enterprises in Ukraine, fixed costs are distributed in proportion to direct wages and our break-even calculations at a number of machine-building enterprises showed that using the distribution of wages as a base, in order to achieve break-even, it is necessary to increase the production volume of unprofitable products and reduce profitable ones, which clearly contradict common sense. That's why we can confirm that break-even calculations are not carried out at Ukrainian enterprises at all.

Thus, the profit margin calculation methodology bases on the concept of fixed costs distribution in proportion to the profit margin is proposed to Ukrainian corporate management and uses in calculations of this research.

\section{Results}

\subsection{Proofs of the concept of fixed costs distribution in proportion to the profit margin}

Long-term research on the examples of machine-building enterprises led us to the conclusion that in the multiassortment production conditions on the way of real calculations of profit, prime cost, cost-effectiveness and the formation and adjustment of prices, there is a controversial problem of fixed costs distribution between types of products. In general, the choice of the base distribution is subjective and, therefore, choosing the base, we set the prime cost value in advance. Depending on the distribution base, we can get several prime cost values. Does this mean that there can be several managerial decisions?

In Economist magazine we published an article "Do the ends always justify the means? How to distribute conditionally fixed costs" [18], where for the first time it was proposed to distribute fixed costs in proportion to the profit margin. What considerations did we proceed when justifying this method from? Margin theory underlines that at the break-even point the profit margin is equal to fixed costs. Therefore, having determined the break-even points and the profit marginal amount for these volumes, we can actually determine the amount of fixed costs for each group of products. Since a priori it cannot be that for the calculation of break-even (as the balance of fixed costs to relative profit margin) there can be one value of fixed costs, and another for calculating the cost.

As a matter of fact, a number of proofs that for the distribution of fixed costs only the profit marginal should be used as the distribution base is given in addition to this provision, and some of these proofs are presented below.

The first proof. Foreign economists in their works suggest break-even calculations using the average weighted profit marginal, which are based on the relative weight of each product in physical or value terms [19] and similar calculations are presented in many works 
of Ukrainian and Russian scientists. They are extremely complicated and it is almost impossible to produce them if the number of products exceeds ten. But the most important thing is that the results of these calculations completely coincide with the break-even calculations using the break-even ratio (formula 1):

$$
B E R=F C / P M,
$$

where $B E R$ - break-even ratio,

$F C$ - fixed costs,

$P M$ - enterprise profit margin

At the same time, there is no need in the calculations to take into account the relative weight of each product group, as the requirement for the invariability of the assortment structure is observed in calculations, then to achieve break-even it is necessary to increase the production of each group of products by $10 \%$.

The second proof. A. Upchurch, and after him many other authors, in their calculations give break-even indicators for types of products, but do not bring these calculations to indicators of profit and cost-effectiveness, as they practically do not calculate the value of fixed costs by product types. These calculations are not difficult at all, since they have data on the values of direct costs, prices and break-even points by product types.

Taking into account calculations, it is known that the break-even point for product types is determined by the formula 2:

$$
B E P_{i}=F C_{i} /\left(P_{i}-V C_{i}\right),
$$

where $B E P_{i}$ - break-even point for product types,

$F C_{i}, V C i, P_{i}-$ fixed costs, variable costs and price for product types.

Since in these calculations the values of $B E R, P$ and $V C$ are known and calculated, it is easy to calculate the value of fixed costs (formula 3 ):

$$
F C_{i}=B E P_{i} \cdot\left(P_{i}-V C_{i}\right)
$$

Therefore, it isn't also difficult to calculate the prime cost and profit by product types as information on price and variable costs is available in the original version.

In is to understand, why do foreign and domestic scientists do not use the break-even calculations to the indicators of prime cost, profit and cost-effectiveness by product types? Perhaps, because in this case it would be necessary to recognize that the most optimal method of allocating fixed costs is a marginal approach.

The third proof. The formula of BER indicator can be derived from the well-known formula of "break-even turnover", widely used in economic literature:

$$
B E T=F C / P M R,
$$

where $B E T$ - break-even turnover;

$F C$ - fixed costs;

$P M R$ - profit margin ratio for the whole enterprise, which is calculated as the relation of profit margin $(P M)$ to sales revenue $(S R)$ that is (formula 5):

$$
P M R=P M / S R
$$

Therefore, $B E T$ indicator formula can be transformed as follows (formula 6):

$$
B E T=\frac{F C}{P M} \times S R
$$

According to proposal the break-even ratio formula will look like formula 7 :

$$
B E R=F C / P M
$$

Thus, the break-even calculations method can be reflected as formula 8 :

$$
B E T=B E R \times S R
$$

The results of the break-even calculations according to formulas 4 and 8 are identical, but if formula 4 allows you to calculate the break-even turnover only for the whole enterprise, then using profit margin you can calculate the break-even turnover in physical and value terms both for the whole enterprise and for individual products types, and also to distribute fixed costs by product types. Thus, on the one hand, with the help of the margin of safety $(M O S)$, which is directly related to $B E R$, we can calculate the enterprise profit (loss) as a whole by formula 9 :

$$
M O S=1-B E R
$$

And on the other hand, we can calculate profit (loss) for individual product types by formula 10 :

$$
P_{i}=\operatorname{MOS} \times P M_{i},
$$

where $P M_{i}-$ is the profit margin for the $i$-product type.

And the fourth proof. Only with the distribution of fixed costs in proportion to the profit margin using $B E R$ the observance of the $C V P$ system limitation is ensured, i.e. the invariance of the assortment structure when calculating the break-even by product. All other distribution bases distort the assortment structure.

\subsection{Calculation system of profit margin and price indicators according to the profit margin concept}

The concept of fixed costs distribution in proportion to the profit margin has its own assumptions. It is assumed that all fixed costs (including production costs) are irrelevant for making management decisions. Since fixed costs can be partially semi-variable or semi-fixed, this approach can affect the accuracy of product prime cost calculations. It should be noted that all methods of allocating fixed costs always allow some element of inaccuracy. "The best that can be counted on," notes A. Upchurch, "is to get an acceptable result that minimizes such inaccuracy" [20].

But the essence of the problem lies in the fact that the accuracy of calculating the prime cost, though it may sound paradoxically, does not really matter in managing costs, profits, cost-effectiveness and prices by product types. Actually, the purpose of this article is to disclose the relationship between all elements of the calculation in 
this system and identify those of them that play the main role. But to find out these relationships, and at the same time to check the realistic assumptions in the distribution of fixed costs, it is possible only by conducting empirical studies on examples close to reality, which will ensure the reliability of the recommendations proposed on their basis. The results of calculations are presented in table 1 .

According to the table 1 , for this example $B E R=$ $1104 / 1380=0.8 ; M O S=0.2 ; P=1380-1104=276$.

With the help of MOS we can easily calculate the profit on products without preliminary calculation of the prime cost. So, for product "A" the profit is: $0.2 \times 8=1.6$ and for the volume: $0.2 \times 480=96$. But for our research it is very important to find out how the cost will behave under certain changes. In table 1 it is necessary to note that for products " $\mathrm{A}$ " and " $\mathrm{C}$ " the indicators of $P M R$ and cost-effectiveness are 0.4 and 8.69 , respectively.

Due to market conditions changes, the following modifications have occurred in the product range:

\section{Product "D" was discontinued.}

2. Variable costs for product "C" have decreased by 1.2 units. Thus, there are two possible options. The first is to keep the same price, which will lead to an increase of cost-effectiveness, but taking into account the current market situation, it will lead to sales decrease. The second is to reduce the price, keep the same costeffectiveness with $P M R=0.4$ and thereby sales will increase by 30 units and the enterprise has chosen the second option.

3. The enterprise has accepted an order for the product "E" with variable costs of 14, production of 20 units and decided to include cost-effectiveness into price at the level of product "B" with $P M R=0.5$.

According to these calculations we have such results:

For product $\mathrm{C}$. The price is calculated using the formula:

$$
P R_{\text {ini }}=\frac{V C_{i}}{1-P M R} .
$$

Thus, the results of calculations according to this formula, in which fixed cost are not taken into consideration and hence the prime cost too, are: $P R_{C}=4.8 /\left(1^{\smile} 0.4\right)=8$; $P M_{i C}=8 \triangleleft 4.8=3.2 ; P M_{C}=3.2 \times 50=160$.

So, for the newly ordered product "E" we have the following results: $P R_{E}=14 /(1 \smile 0.5)=28 ; P M_{i E}=28 \smile 14=$ 14; $P M_{E}=14 \times 20=280$. As a result, the profit margin for the enterprise will amount: $480+720+160+280=1640$; fixed costs increased by 44 units and amounted about 1148. And thus we can observe new values of $B E R$ and $M O S: B E R=1148 / 1640=0.7 ; M O S=0.3$; $P=1640 \backsim 1148=492$.

According to calculations we can analyze the results. For products "A" and "B" practically no changes occurred either in prices, sales volumes, or in the value of variable costs, but there was a redistribution of fixed costs. The decrease in fixed costs for these products by 120 units was taken over by products "C" and "E", which led to a decrease in the prime cost and increase in profit for products "A" and "B" by 120 units and a significant increase in their cost-effectiveness. For product "C" the price was reduced by $20 \%$, which ensured the volume of sales up to 50 units, the previous value of $P M R=0.4$ remained and costeffectiveness increased from $8,69 \%$ to $13,6 \%$. New product "E", in price of which we have included $P M R=0.5$, i.e. at the product " $\mathrm{B}$ " level, is sold with cost-effectiveness of $17,6 \%$, as in the case with product " $\mathrm{B}$ ". Thus the question can be put, what conclusions can be drawn from these examples?

First of all, in the conditions of multi-assortment production, the cost of goods by type of product is not a subject, but an object of calculations, as its value cannot be determined in isolation from changes in the structure of product assortment. Therefore, in these conditions, it is impossible to set the task of determining the "target cost" and "target profit" and, naturally, the cost price by type of product cannot be the basis for the prices formation and adjustment.

Secondly, these examples clearly show that the decisive role in the calculations is played by the "margin profit ratio" by product type. With the help of $P M R$ certain level of comparative cost-effectiveness, can be included in calculations, price changes can be made and what is of great importance, there can be formed prices for new orders. The proposed pricing formula fully meets the requirements of anti-cost (value) pricing, the supporters of which completely reject participation of full cost in pricing. "If, when setting prices, one proceeds from full costs," R. J. Dolan note, "as it occurs in practice, the price is determined by fixed costs, and this is logically incorrect" [21]. Fixed costs do not take part in the proposed pricing formula (11), but with the help of $P M R$, such a level of marginal profit is included in the calculation, which allows you to cover fixed costs and generate a profit with a given level of cost-effectiveness.

Thirdly, it should be noted that, in fact, using $P M R$, we form a comparative cost-effectiveness by product types, regardless of changes in the assortment structure. Scientific approach towards economic situation demands thorough analysis of all indicators and components but in practice employees of industrial enterprises are not aware of the existence of such indicator as "profit margin ratio" $(P M R)$, and in the economic literature and textbooks its role is not given much attention.

Quantitative measurements suggested by our author's group as a margin calculation methodology are developed specially for the most profitable machine-building enterprises of Khmelnytskyi region with the aim of their corporative management improvement.

Analyzing proposed materials of Public Joint-Stock Company "Temp" it was realized that it has purchased a laser machine at about UAH 5 million and usage of this equipment has led to a reduction of materials cost, wages and technological energy for products manufacture. Fixed costs distribution proportionally to wages led to an increase of distribution ratio, because fixed costs have increased due to depreciation, and enterprise wages decreased as a whole. In this case, fixed costs for the products processed on this machine decreased, and accordingly the entire "load" of fixed costs increase due to depreciation 
Table 1. Calculation of prime cost, profit and cost-effectiveness in the distribution of fixed costs proportionally to the profit margin

\begin{tabular}{ccccccccccccc}
\hline \multirow{2}{*}{ Products Quantity } & \multicolumn{1}{c}{ Price and revenues Variable costs Profit margin Fixed costs Prime cost Profit Cost-effectiveness } \\
\cline { 2 - 26 } & $P R$ & $R$ & $V C_{i}$ & $V C$ & $P M_{i}$ & $P M$ & $F C$ & $P C$ & $P$ & $P M R$ & $C E, \%$ \\
\hline A & 60 & 20 & 1200 & 12 & 720 & 8 & 480 & 384 & 1104 & 96 & 0.4 & 8.69 \\
B & 40 & 36 & 1440 & 18 & 720 & 18 & 720 & 576 & 1296 & 144 & 0.5 & 11.1 \\
C & 30 & 10 & 300 & 6 & 180 & 4 & 120 & 96 & 276 & 24 & 0.4 & 8.69 \\
D & 20 & 12 & 240 & 9 & 180 & 3 & 60 & 48 & 228 & 12 & 0.25 & 5.26 \\
\hline$\sum P$ & 150 & & 3180 & & 1800 & & 1380 & 1104 & 2904 & 276 & 0.436 & 9.5 \\
\hline
\end{tabular}

Table 2. Calculation results with account changes

\begin{tabular}{ccccccccccccc}
\hline \multirow{2}{*}{ Products Quantity } & \multicolumn{1}{c}{ Price and revenues Variable costs Profit margin Fixed costs Prime cost Profit Cost-effectiveness } \\
\cline { 2 - 32 } & $P R$ & $R$ & $V C_{i}$ & $V C$ & $P M_{i}$ & $P M$ & $F C$ & $P C$ & $P$ & $P M R$ & $C E, \%$ \\
\hline A & 60 & 20 & 1200 & 12 & 720 & 8 & 480 & 336 & 1056 & 144 & 0.4 & 13.6 \\
\hline B & 40 & 36 & 1440 & 18 & 720 & 18 & 720 & 504 & 1224 & 216 & 0.5 & 17.6 \\
\hline C & 50 & 8 & 400 & 4.8 & 240 & 3.2 & 160 & 112 & 48 & 0.4 & 13.6 \\
\hline D & 20 & 28 & 560 & 14 & 280 & 14 & 280 & 196 & 476 & 84 & 0.5 & 17.6 \\
\hline$\sum P$ & 170 & & 3660 & & 1960 & & 1640 & 1148 & 3108 & 492 & 0.455 & 15.8 \\
\hline
\end{tabular}

has moved to the of products prime cost that were not processed on this equipment. With the distribution of fixed costs proportionally to the profit marginal, the situation is exactly opposite. Since the increase of profit margin (and profit) was greater than the increase of fixed costs, then the profit margin ratio and cost-effectiveness increased for the products processed on this machine, the profit margin despite the fact that they have taken on the "load" of fixed costs. However, for other products such like situations have led to a positive profit increase.

Thorough research of Public Joint-Stock Company Krasilovagromash economic situation, we carried out similar calculations in connection with the introduction of new equipment that was used for some products and obtained similar results. With the distribution of fixed costs proportionally to wages some of low-profit products, in production of which no new equipment was used, turned into unprofitable ones.

These two examples (and there could be given much more of them) prove certain threats for enterprise financial condition in case wrong decisions would be taken and, at the same time, such examples can be of significant importance in making business decisions. And vivid proof of such like conclusions can be the advice of E. A. Helfert, who wrote: “... common sense suggests that most of the analytical efforts should be directed to those areas where the probability of insufficient analysis is the greatest ..." [22].

Generally speaking, it is very difficult to break the stereotypes that have evolved over the centuries, and that the proposal, when setting prices and profits, does not take into account the production prime cost as the main component is rather provocative, but at the same time, we are sure that in the sphere of manufacture of production technically purposed products, this technique has the right to life and that in the near future it can be widely used.

\section{Conclusions}

The corporate management mechanism provides such conditions of its functioning that ensure stability of the companies and enterprise development. Corporate management contains a wide complex of tasks, especially in conditions of multi-assortment production but absence of analytic instruments doesn't support the precise evaluation of decision making results of well grounded managerial solution. That's why the variability directions of corporate management should be considered at the new and, at the same time, effective basis as profit margin concept with fixed costs distribution in proportion to the profit margin methodology proposed in this article for Ukrainian enterprises.

Summarizing research results the following conclusions can be given:

1. The proposed base for fixed costs distribution in proportion to the profit margin transforms the distribution system into a system for managing costs, prices, profits and cost-effectiveness by product types.

2. Fixed costs and marginal profit are a kind of "black boxes" that collect and store all information on volume changes and assortment structure, prices and prime costs, which can be used in any moment to carry out the necessary calculations with the help of $B E R$ and $M O S$.

3. In the conditions of multi-assortment production, the prime cost by product type cannot be formation and adjustment basis of prices, since it strongly depends on changes of production volume and assortment structure of the whole enterprise.

4. Products with the same $P M R$ will be of the same cost-effectiveness regardless their production volume. 
5. The proposed pricing formula on anti-cost basis can be used for "value" pricing. The degree of "value" should be correlated with the value of $P M R$ in price calculation.

6. Prices changes are advisable by product types in case of variable costs increase or decrease using the profit margin ratio in order to ensure given costeffectiveness.

Thus, it is necessary to admit that the most important tool in proposed profit margin concept is the "margin ratio" by product type, because it provides price formation on the anti-cost basis and with its help the required level of cost-effectiveness is set. The role of this indicator in the economic literature is underestimated and in practice it isn't simply used. The proposed calculation formulas have a direct effect, do not require additional time and resources are easy in use and have internal logic. Consequently, different companies can profitably use suchlike methodology for expenditure decrease and therefore in profit and production volume increase. Suggested methodology is advisable for any corporate management system as it can assist in improvement of such indicators as profit margin and cost-effectiveness.

\section{References}

[1] W. Baumol, A. Blinder, Economics: Principles and Policy (New York, 1979)

[2] H.A. Simon, The Quarterly Journal of Economics 69, 99 (1955)

[3] M.H. Birnbaum, Journal of Mathematical Psychology 48, 87 (2004)

[4] R. Coase, Journal of Economics \& Management Strategy 15, 255 (2006)

[5] F.v. Hayek, American Economic Review 79, 3 (1989)

[6] P. Novák, B. Popesko, Economics \& Sociology 7 (2014)
[7] R. Lin, Z. Chen, Applied Mathematical Modelling 40, 5377 (2016)

[8] K. Janovská, S. Vilamová, M. Piecha, J. Kutác, R. Kozel, J. Citbajová, E3S Web Conf. 134, 03015 (2019)

[9] A. Birca, Problemy sovremennoi nauki i obrazovaniia $\mathbf{5}, 55$ (2017)

[10] A. Ogbo, C. Orga, T. Adibe, Industrial Engineering Letters 2, 47 (2012)

[11] M. Potkany, L. Krajcirova, Procedia Economics and Finance 26, 194 (2015)

[12] P.T.M. Ingenbleek, R.T. Frambach, T.M.M. Verhallen, Journal of Product Innovation Management 30, 560 (2013)

[13] D. De Toni, G.S. Milan, E.B. Saciloto, F. Larentis, Revista de Administração (São Paulo) 52, 120 (2017)

[14] A. Farm, Journal of Post Keynesian Economics 43, $61 \quad$ (2020), https://doi.org/10.1080/01603477.2019.1616562

[15] R. Luostarinen, M. Gabrielsson, Thunderbird International Business Review 48, 773 (2006)

[16] B. Cohen, M. Neubert, ISM Journal of International Business II, 27 (2017)

[17] O. Orlov, K. Dumanska, N. Ponomaryova, D. Kobets, E3S Web of Conferences 166, 12002 (2020)

[18] O. Orlov, Y. Ryasnykh, Economist pp. 45-49 (2001)

[19] A. Atkinson, R. Kaplan, E. Matsumura, S. Young, Management Accounting: Information for DecisionMaking and Strategy Execution (Pearson, London, 2012), ISBN 9780137024971

[20] A. Upchurch, Management Accounting: Principles and Practice (Ft Pr, 1998)

[21] R. Dolan, Evernote (B): Announcing a Pricing Plan Change (2019), harvard Business School Supplement 519-036

[22] E.A. Helfert, Financial Analysis Tools and Techniques: A Guide for Managers (McGraw-Hill Education, New York, 2001) 